\title{
Millennials' Use of Terms of Endearment in Casual Conversation in Digital Communication
}

\author{
Yusnita Febrianti* \\ Department of English \\ Universitas Negeri Malang \\ Malang Indonesia \\ *yusnita.febrianti.fs@um.ac.id
}

\author{
Teuku Muhammad Ridha Al Auwal \\ Department of Language and Arts \\ Universitas Samudra \\ Aceh, Indonesia \\ teuku.alauwal@unsam.ac.id
}

\begin{abstract}
Modern forms of communication have made it possible that relationships are not determined by physical proximity. Technology advancement opens the opportunities for members of society to construct relationships over a long distance by means of online chatting platforms. Among the many platforms is WhatsApp, which is common in Indonesia. The present study focuses on the observation that technology brings about a shift in the use of terms of address. Despite the distance, users of online chats, particularly millennials, tend to use terms of endearment. It can easily be spotted that more and more young people are likely to prefer to use more modern, communicative, and intimate languages within their daily communication. As a result, a regular shift in using terms of endearment amongst millennials seems inevitable in today's situation. This paper explores the current trends of using terms of endearment as address between interlocutors in casual conversation through chats in digital communication. Foregrounded by theories in Sociolinguistics, the study uses content analysis in processing and interpreting the data in the form of chat screenshots obtained from the volunteer participants. The data analysis is useful to reveal two important information. First, it shows the variety of terms of endearment used by the participants as a form of address. Second, this result provides insights on the degree of closeness indicated from the use of the terms of endearment as address.
\end{abstract}

Keywords-language shift, terms of endearment, terms of address, closeness, digital communication

\section{INTRODUCTION}

Language is one of the most significant aspects of human life. It is a form of expression where people are able to share ideas and express themselves during both face-to-face and online interactions. In today's situation, digital communication through its online platforms such as email, Facebook, Instagram, WhatsApp, and other forms of social media seems inseparable from people's everyday life especially millennials, known as native speakers of internet language, who were born and raised amid new technology era [1]. Not only are those state-of-the-art tools of communication considered more sociable, but they are also much 'faster and more convenient' [2]. That is why the use of online communication has grown rapidly in the community around the world in recent years. This has brought about changes in language use. The present study observes the specific language shift in digital communication i.e., in relation to the use of terms of endearment. A variety of terms of endearment are used as address by communicator, indicating a certain degree of closeness between them. Therefore, the data analysis and interpretation in the study are intended to unpack the variety of terms of endearment used as address and how they are used to hint at the degree of closeness between the communicators.

\section{LITERATURE REVIEW}

This section provides a brief review of relevant literature for the analysis of data in the study. The section begins with a broad overview of the language choice, the shift, and the use of terms of endearment. The main argument for the study is built on the notion that terms of endearment is supposed to be used to show politeness. Overall, the review is useful to inform the content analysis in the data analysis process.

\section{A. Language Choice}

The first relevance on the issue of using certain terms of endearment as address deals with that of the language choice. The preference of one language over another for different purposes and various contexts is known as language choice [2]. The process of language choice during the communication is mostly influenced by the aims and contexts of communication [3] and also cannot be separated from the social, cultural, and lifestyle aspects [4,5]. For instance, a study conducted by Smith-Hefner's [6] ethnographic study on Javanese people in Yogyakarta revealed that the younger generation prefers to speak Indonesian instead of Javanese in their daily communication because it seems more modern, egalitarian, communicative, intimate, and participatory. These findings are similar to those found in Al-Auwal [7] reporting that Acehnese youths in Banda Aceh are used to speaking Indonesian in almost every interactional setting. This is simply because they believe that Indonesian is more modern, prestigious, convenient, romantic, and cooler whilst Acehnese sounds harsh and weird. They admitted that they only use Acehnese for 
making jokes, humour, and puns. This research are examples of language choices in the broader scopes.

In a more specific member of demography, language choices are seen in the youth groups. Young people are also accustomed to mixing languages while interacting nowadays. Blending linguistic forms, known as code-mixing and switching, becomes so ubiquitous amongst younger generations. Such situations are found in both face-to-face and online communications. They frequently utilize new terms in which older generations will find it difficult to understand [8]. It is not unusual to find that more and more young people favour this style of communication in their daily life. If the patterns of individual language use and choice keep changing, there is no doubt that language shift is in progress within a community [9].

\section{B. Language Shift}

Language shift has attracted a high level of attention of bilingual and/or multilingual communities around the world including Indonesia, as one of the most linguistically diverse countries that have around $10 \%$ of the world's languages [10]. The process of language shift does not only occur as the result of the disappearance of the native speakers, yet it simply because one language is considered more communicative and expressive and also able to accommodate and meet the needs of surroundings than its counterpart languages [11]. Therefore, the topic of language shift is significant to be explored particularly in digital communication in order to improve our understanding of the relationship between language and new technology and/or the internet such as social media [3].

Tagliamonte [1] argues that the internet is not the sole factor leading to language change and shift since language itself is dynamic and keeps changing over time. However, one of the main findings of Coats' [12] study is that language shift towards English currently occurs amongst young people in the Nordic countries especially on the social media platform, namely Twitter. The use of languages other than mother tongue is not uncommon during online interaction compared to faceto-face communication [12]. However, according to Musgrave [13], also supported by Abtahian and Cohn's findings [10], the shifts occurring in many places including in Indonesia should be seen as 'changing patterns of multilingualism' instead of viewing as 'shifts of large populations from one language to another'. It is, therefore, critical to explore the language shift in online communication. This study takes on a special focus on the use of terms of endearment as address amongst millennials in Indonesia.

\section{Digital Communication and Shift in Politeness as Reflected in the Terms of Address}

The expansion of digital communication has likely led to the emergence of linguistic change amongst youths. Cook [3] argues that the new technology such as the internet and social media has developed 'new hybrid forms of interaction' and created 'new styles, conventions, and modes of written expression', which then lead to a new variety of language, well-known as Netspeak [14]. The term 'Netspeak', introduced by Crystal, is commonly used to refer to the digital communication codes used by netizens, where a mixture of spoken and written forms is normally found during the communication [2]. While it is argued that face-to-face communication offers more features of non-verbal cues and gestures during the communication, the use of emoticons, stickers, animations are widely used as a better alternative' in today's world [2]

As a result, these new technologies and global media have unavoidably driven young people to become the pioneers of linguistic and interactional change [3]. The emergence of online communication is widely believed to impact linguistic ecology, which may lead to either language shift or language maintenance [15]. It means that there is a potency that digital communication is likely to shift the way people communicate with each other. To say "[i]f the Internet is a revolution, therefore, it is likely to be a linguistic revolution" may not be an exaggeration [14].

The concepts of politeness within online communication have also gained much attention for the last few decades. Politeness is commonly believed as part of behaviour or attitude that has been socially and culturally accepted as a norm within a particular community. According to Blum-Kulka [16] politeness is "the interactional balance achieved between two needs: the need for pragmatic clarity and the need to avoid coerciveness".

The concept of politeness varies across cultures and speech communities [17,18]. It is a dependent aspect that is unlikely separated from social contexts and circumstances [18]. The contexts in the given situation are extremely important in analysing politeness within intra- and intercultural communication. As suggested by Meier [19], politeness is determined by the contexts of social, linguistics, and cultures either interculturally or interculturally. Hence, analysing the notion of politeness should be focused and concerned more on the sequence of proper communication and interaction, based on the degree of familiarity and formality, and the contexts of situation, age, and gender [17].

The use of address terms, in many cultures, needs to be fully understood in order to avoid miscommunication and misunderstanding between speakers and interlocutors. Bowe and Martin [17] gave examples about the polite forms of addressing such as Vous and Vos/Usted as polite secondperson forms of French and Spanish respectively. According to Brown and Gilman (1960 cited in [17]), the issue of power and solidarity strongly influences the usage of addressing terms. The term preference is inevitably influenced by age of the speaker and interlocutor, social status, and social distance [17]. Thus, it is presumed that the use of terms of endearment plays a significant role in online communication to maintain social cohesion and to show closeness and intimacy between speakers during the conversations. 


\section{METHODOLOGY}

The study is qualitative in nature, wherein the analysis results are presented in description. The participants in this study are 70 users of WhatsApp chats. They are both male and female users aged between 25 and 30 years old. They were requested to participate in an online survey to gather information for the study. The survey resulted in two main important data sets for the study. First, the participants are required to submit screenshots of chats showing the terms of address that they use in the digital conversation. This dataset is useful to gather information on the variety of terms of endearment used by the participants as a form of address. The next dataset is statements from the participants regarding their reasons to use such terms of address in their casual conversation. This dataset is useful to draw a map of function for the terms of endearment used as address in the casual conversation. Data analysis procedure is mainly conducted using a content analysis. Description of both stages in the analysis are presented in the following section.

\section{RESULTS AND DISCUSSION}

In the data analysis, terms of address are separated from the overall content of the conversation. It is clear that the terms of address are only a minor part compared to the content of the conversation. As a matter of fact, terms of address are not the content of the conversation. Nevertheless, they have important roles in providing hints of the constructed relationships between the participants involved in the conversations. In light of the data analysis results, the following issues are found: the variety of terms of address used by the participants and the degree of closeness indicated from the terms of address.

\section{A. Variety of Terms of Endearment used as Address}

A majority of the participants in the study, namely $84.3 \%$ (Fig. 1) admitted that they use terms of endearment in casual conversation through digital communication. Fig. 2 shows the results from a further interview to reveal the top four of the terms of endearment, namely beb (34.8\%), followed by sis (14.5\%), say (13\%) and bro (5.8\%). More details of the origins for each term of endearment are provided in Table 1.

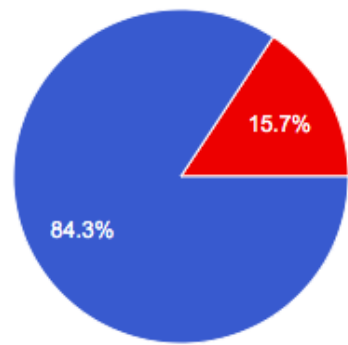

Fig. 1. Number of participants who used terms of endearment in casual conversation.

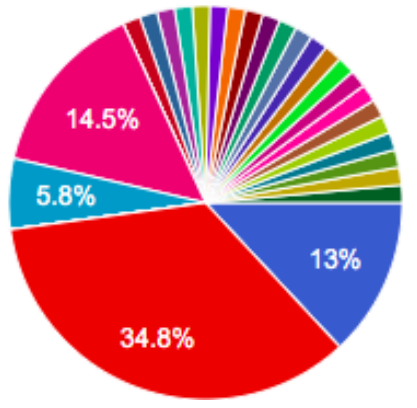

Fig. 2. The top four variation in terms of endearment in casual conversation.

While the top four terms of endearment are only beb, sis, say and bro, more variations are found in the actual conversation. Table 1 shows that terms of endearment used in the casual conversation through digital communication are conducted using a variation of address that are originated from different languages. The predominating terms of endearment originated in English. Some others are found from Indonesian and regional languages.

TABLE I. VARIATION OF TERMS OF ENDEARMENT USED IN THE CASUAL CONVERSATION AND THEIR LANGUAGE ORIGINS

\begin{tabular}{|l|l|}
\hline \multicolumn{1}{|c|}{ Variation of terms of endearment } & \multicolumn{1}{|c|}{ Origins of language } \\
\hline Beb, by, bebz, babe, bb & English \\
\hline Darl, darling & English \\
\hline Bro, dude, man, mate & English \\
\hline Cin, cyin & Indonesian \\
\hline Kak & Indonesian \\
\hline Sayang, say, seyeng & Indonesian \\
\hline Jeng, neng, lur, cuy & Regional languages \\
\hline
\end{tabular}

In the study, most of the participants use $b e b$ as the selected terms of endearment to name the other participants in the conversation. The term beb originated from the English word baby. In spoken discourses, this word is used as a term of endearment between couples. In this use, it experienced adaptation in the spelling, adopting its Indonesian version of the pronunciation i.e., the English /beib/ into its slightly simpler Indonesian adaptation of $/ \mathrm{beb} /$. Other variation from this word also emerges such as $b y, b e b z, b a b e$, and $b b$. A more gender related address for male interactants is found in different variations namely bro, dude, man, and mate. A more gender-neutral address, on the other hand, is found as darl or darling. From Indonesian origin, the word sayang is used as it is. Variation, however, emerge as a short form of say. Still, another variation is found as seyeng. In addition, variation such as cin and cyin are found as a contraction of the word cinta. Note that both of the Indonesian word origins mean 'love'.

A number of terms of endearments used by the participants are useful to address both male and female participants. The data gathered in this study indicate that the member participants of the chats are those who have known each other for a number of years. Identity details such as gender and age are obviously known between participants. While these 
participants could have used names or nicknames to address each other, using terms of endearments is included as a preferred option. In this case, unisex terms of endearments are applicable for both male and female participants. Interestingly, terms of endearment originated in English are not capable of fulfilling this function due to the masculine and feminine markers in the English pronouns. This is better served by local and Indonesian origins in terms of endearment such as lur, kak and cuy. Lur is the short form of dulur, literally means brothers or sisters. This word is stemmed from a Javanese word that does not indicate masculinity, femininity nor age gaps. Kak is a short form of Kakak, an Indonesian word that is used to address someone older, either male or female. Cuy, on the other hand, has recently been popular as a term of address that is used to simply address anyone, male, female, younger, older, familiar, and unfamiliar. This term is some sort of 'street word' to greet anyone for small talk purposes

\section{B. Function of terms of endearment in casual conversation}

Participants in the study reported that they use terms of endearment with people that are familiar to them. Fig. 3 shows the details of the length of relationship between communicators in the study. This account for $53.5 \%$ of the participants who used the terms of endearment with friends that they know for more than 3 years. A quarter other, however, used them with friends that they know between 1 and 3 years. This number is followed by participants who know their communicator for only less than 1 year $(21.1 \%)$.
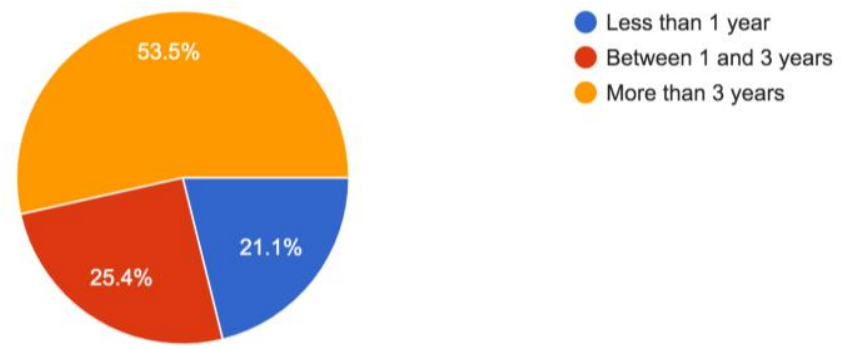

Fig. 3. Length of relationship between communicators

Further interview with the participants is gathered to obtain information about the reasons why they used such terms of endearment for address. While the study involved 70 participants, the answers can be categorized into three groups. They are keeping up with the trends, making jokes and showing closeness.

Apparently, the use of terms of endearment to address communicator in digital communication has become a trend among the millennials. Therefore, participants are using such terms of endearment in order to keep up with the style of language use in digital communication. In the list below, the participants' statements are shown to justify this claim.

- Just following the trend

- Because I think it's cool to use such terms of address
- I often use 'beb' because this is trending nowadays. This word also makes chat more lively and more friendly.

One participant admitted that using such terms of endearment for address is 'just following the trend'. Another participant's opinion in this matter reveals that he or she 'thinks' that 'it is cool' to get involved with the hype. Another statement mentioned that such term is 'trending nowadays' and it makes the chat 'more lively and friendly'. All in all, the attempts to use a trendy language use are a way for language users to be accepted in the society wherein the language is used.

On the other hand, a number of participants consider using the terms of endearment for address is a type of jokes. Look at the following list:

- Just for jokes without any other purpose

- Because it sounds funny and friendly.

- Because we are cool enough to use such terms as a joke

Reasons such as 'just for jokes', 'being funny and friendly' and 'cool' indicate the impact made by the use of term of endearment as address. To some extent, for the users of digital communication, terms of endearment as address may function to decrease tension in the conversation. It is unfortunate, however, that the study does not probe further into the terms and condition in which using such terms can be used as jokes. In the case where the communicators are not familiar to each other, such terms may create misunderstanding.

One third of the participants in the study answered that the main reason why they use terms of endearment on their casual conversation through digital communication is either to show their closeness or build closeness with the other participants. The indication of the use of terms of endearment to show the closeness between participants is the fact that the terms of endearments are used mutually and reciprocally between the members of the participants in the chats. The following are the statements from the participants in regard to the use of terms of endearment to indicate closeness:

- The reason why is because it simply shows closeness between that person and me.

- I just like to use that term. It means they're special to me and I consider them as a close person to me.

- Simply because they're my closest friends, I can talk about everything with them without any worries, they make me feel happy. They always there for me, caring about my well-being.

- Simply because they're my closest friends. We always feel comfortable and support each other. Their love and care are meant to me.

- Because we are close enough, and the conversation will go more relax

- To get closer with that person 


\section{- It makes us feel closer}

More than half of the whole participants in the study stated that they use terms of endearment with friends they know for more than three years. Relevant to this, the first five of the reasons listed above indicate that the participants have close relationship with the interactants. The rest of the example from participant statements above indicate that they use the terms of endearment with people they know for between one and three years. This is in line with Eggins and Slade's [20] suggestion that naming is one of language features that can create closeness between participants in casual conversations. probably the way that they can build closeness with the particular people. Interestingly, some participants in the study are those with considerable age gaps. It has been a part of common Eastern Culture that older people are to be addressed with particular titles or naming indicating their age as a form of politeness. However, this study has found that intimate terms of address diminish age gaps. This creates a certain indication of degree of closeness. For some reasons, it is clear that the participants do not mind using such terms with each other.

\section{CONCLUSION}

Overall, the study has shown that the use of terms of address is an important source of information in understanding the construction of relationships between participants in casual conversation. A variation of terms of endearment are used in the study using a range of words originated from English, Indonesian and regional languages. They are used to show how relationships are shown and built through this minor part of the conversation. Also, they can be mapped into different functions such as to keep up with the trend, making jokes and showing closeness between communicators.

The study gathered information from casual conversation conducted through digital chatting platforms. While the data provides information in terms of organized structure of turn taking, content and use of terms of endearment, it lacks additional sources that could have multiplied the meaning making of the use of the terms of endearment. The additional sources of meaning include paralanguage such as gestures and gazes that may be clearer in face-to-face conversations [21]. Subsequent studies on the use of terms of endearment in casual conversation may include modifications in the number of participants. Case studies in casual conversation will provide in-depth analysis on the building of involvement or relationships between participants in extended conversations. On the other hand, a massive scale recruitment of participants will provide useful information whether the use of terms of endearment in casual conversations is a temporary trend or a phenomenon of a language shift that occurs locally or globally.

\section{REFERENCES}

[1] S. Tagliamonte, "So sick or so cool? The language of youth on the internet," Language in Society, vol. 45, no. (1), pp. 1-32, 2016.
[2] F. Fahmee and Y.M. Fung, "Language Choice in Online Written Communication among Maldivian Professionals," 3L: The Southeast Asian Journal of English Language Studies, vol. 22, no. (2), pp. 49-66, 2016

[3] S. Cook, "New Technologies and Language Change: Toward an Anthropology of Linguistic Frontiers," Annual Review of Anthropology, vol. 33, pp. 103-115, 2004.

[4] J.A. Fishman, Reversing language shift: Theoretical and empirical foundations of assistance to threatened languages. Clevedon Multilingual Matters, 1991.

[5] H.Y.H. Lee, "Bargirl Style of Language Choice and Shift: A Tale from the Land of Smile," Theory \& Practice in Language Studies, vol. 3, no. (3), 2013

[6] N.J. Smith-Hefner, "Language shift, gender, and ideologies of modernity in Central Java, Indonesia,” Journal of Linguistic Anthropology, vol. 19, no. (1), pp. 57-77, 2009

[7] T.M.R. Al-Auwal, "Reluctance of Acehnese youth to use Acehnese," Studies in English Language and Education, vol. 4, no. (1), pp. 1-14, 2014.

[8] M. Schmid, Language Attrition (Key Topics in Sociolinguistics). Cambridge: Cambridge University Press, 2011.

[9] A.C. Cohn and M. Ravindranath, "Local languages in Indonesia: Language maintenance or language shift," Linguistik Indonesia, vol. 32, no. (2), pp. 131-148, 2014.

[10] M.R. Abtahian and A.C. Cohn, Dynamic multilingualism and language shift scenarios in Indonesia. In S. Drude, N. Ostler \& M. Moser (Eds.), Endangered languages and the land: mapping landscapes of multilingualism (pp. 106-112). London: FEL \& EL Publishing, 2018.

[11] J. Chandras, "Mother tongue activism and language shift in multilingual India: Marathi in Pune, Maharashtra," Critical Asian Studies, vol. 51, no. (4), pp. 579-596, 2019

[12] S. Coats, "Language choice and gender in a Nordic social media corpus," Nordic Journal of Linguistics, vol. 42, no. (1), pp. 31-55, 2019.

[13] S. Musgrave, Language Shift and Language Maintenance in Indonesia In P. Sercombe \& R. Tupas (Eds.), Language, education and nationbuilding: Assimilation and shift in Southeast Asia (pp 87-105). London: Palgrave, 2014

[14] D. Crystal, Language and the Internet. Cambridge: Cambridge Univ. Press, 2001

[15] S.C. Herring, "Computer-mediated communication on the Internet," Annual Review of Information Science and Technology, vol. 36, no. (1), pp. 109-168, 2002.

[16] S. Blum-Kulka, "Indirectness and politeness in requests: Same or different?" Journal of pragmatics, vol. 11, no. (2), pp. 131-146, 1987.

[17] H. Bowe and K. Martin, Communication Across Cultures: Mutua understanding in a global world. Cambridge, New York, Melbourne: Cambridge University Press, 2007.

[18] K.A. Yu, "Culture-specific concepts of politeness: Indirectness and politeness in English, Hebrew, and Korean requests," Intercultural Pragmatics, vol. 8, no. (3), pp. 385-409, 2011.

[19] A.J. Meier, "Defining Politeness: universality in appropriateness," Language Sciences, vol. 17, no. (4), pp. 345-356, 1995.

[20] S. Eggins, Keeping the conversation going: a systemic-functiona analysis of conversational structure in casual sustaine talk (Doctoral dissertation), 1990

[21] Y. Febrianti, E. Westin, T. Vu and J. Yang, "Non-native and Native Speakers' Casual Conversations: A Comparative Study of Involvement and Humour," Pertanika Journal of Social Sciences \& Humanities, vol. 27, no. (2), 2019. 